\title{
Increased Anxiety and Impaired Pain Response in Puromycin- Sensitive Aminopeptidase Gene-Deficient Mice Obtained by a Mouse Gene-Trap Method
}

\author{
Tomoharu Osada'1,2 Shiro Ikegami, ${ }^{1}$ Keiko Takiguchi-Hayashi, ${ }^{1}$ Yukiko Yamazaki, ${ }^{1}$ Yuko Katoh-Fukui, ${ }^{1}$ \\ Toru Higashinakagawa, ${ }^{1}$ Yoshiyuki Sakaki, ${ }^{2}$ and Takashi Takeuchi ${ }^{1}$ \\ ${ }^{1}$ Mitsubishi Kasei Institute of Life Sciences, Tokyo, 194-8511, Japan, and 2Human Genome Center, Institute of Medical \\ Science, University of Tokyo, Tokyo 108-8639, Japan
}

A mouse mutation, termed goku, was generated by a gene-trap strategy. goku homozygous mice showed dwarfism, a marked increase in anxiety, and an analgesic effect. Molecular analysis indicated that the mutated gene encodes a puromycinsensitive aminopeptidase (Psa; EC 3.4.11.14), whose functions in vivo are unknown. Transcriptional arrest of the Psa gene and a drastic decrease of aminopeptidase activity indicated that the function of Psa is disrupted in homozygous mice. Together with the finding that the Psa gene is strongly expressed in the brain, especially in the striatum and hippocampus, these results suggest that the Psa gene is required for normal growth and the behavior associated with anxiety and pain.

Key words: puromycin-sensitive aminopeptidase; anxiety; analgesia; dwarfism; gene trap; enkephalins
In addition to analyses of spontaneous mutant mice, the technology of artificial mutagenesis in the mouse can give us informative insights into higher neuronal functions such as emotion or learning and memory. One methodology, called gene trap, enables us to capture the novel or functionally unknown genes and, at the same time, to generate the corresponding mutant mice (Gossler et al., 1989). In fact, several genes that play crucial roles in mouse embryogenesis have been identified by this method (for review, see Kitajima and Takeuchi, 1999). Although few studies on mammalian neuronal functions using gene-trap methods have been reported, this method also has the potential to identify genes involved in the area.

Here we established a novel mutant mouse line, goku, by a gene-trap method and proceeded more than 14 backcrosses to transfer the trapped allele to a BALB/cA background. goku mutant mice show dwarfism and several behavioral abnormalities involved in anxiety and pain. We also show that the trapped gene, presumed to be responsible for the observed phenotypes, encodes a puromycin-sensitive aminopeptidase (Psa; EC 3.4.11.14) and that the Psa gene was disrupted in the mutant mice.

Psa was purified as a candidate protein for involvement in the extracellular metabolism of enkephalins (Hersh and McKelvy, 1981; McLellan et al., 1988). Other studies suggest that Psa is involved in the inactivation of various neuropeptides such as dynorphins, cholecystokinin, and somatostatin (Hui et al., 1995). However, the functions for Psa in the metabolism of these peptides remain unclear because Psa was found to be a cytoplasmic

\footnotetext{
Received Jan. 28, 1999; revised April 13, 1999; accepted April 26, 1999.

We thank Ichiro Koshino (Veterinary Medical Center, University of Tokyo, Tokyo, Japan) for technical assistance with the measurements of the reference values. We also thank Dr. Takeshi Yagi (National Institute for Physiology, Okazaki, Japan) for thoughtful discussion and critical review of this manuscript.

Correspondence should be addressed to Dr. Takashi Takeuchi, Mitsubishi Kasei Institute of Life Sciences, 11 Minamiooya, Machida, Tokyo 194-8511, Japan.

Dr. Yamazaki's present address: Department of Information Physiology, National Institute for Physiological Sciences, Myodaiji, Okazaki 444-8585, Japan.

Dr. Higashinakagawa's present address: Department of Biology, School of Education, Waseda University, Nishiwaseda Shinjuku, Tokyo 169-8050, Japan.

Copyright (C) 1999 Society for Neuroscience $0270-6474 / 99 / 196068-11 \$ 05.00 / 0$
}

protein (Dyer et al., 1990; Constam et al., 1995). In addition, the specificity of the sequences recognized by Psa is very low, and no inhibitors specific for Psa are known. These facts have made it difficult to elucidate the substrates and functions of Psa in vivo.

Psa-deficient mice may provide a useful model system to characterize the functions of Psa in vivo. Our present studies suggest that Psa is required in the brain for normal behavior.

\section{MATERIALS AND METHODS}

Mice

The goku mouse line was generated using the gene-trap method described elsewhere (Takeuchi et al., 1995). Backcross matings of heterozygous female mice with BALB/cA strain mice were undertaken. goku homozygous mice were generated by intercrossing heterozygous mice with a BALB/cA background. All mice were housed in litters of one to three in cages with sawdust and with free access to food and water. They were maintained in a $12 \mathrm{hr}$ light/dark cycle with lights on at 8:00 A.M. at constant temperature $\left(23 \pm 1^{\circ} \mathrm{C}\right)$.

Experiments involving animals were performed in accordance with standard ethical guidelines for the care and use of laboratory animals (NIH Standards for Treatment of Laboratory Animals, 1985) and approved by the local ethical committee.

\section{5' Rapid-amplified cDNA ends (5'-RACE)}

To obtain fragments of goku cDNA, we used a $5^{\prime}$-AmpliFinder RACE Kit (Clontech, Palo Alto, CA) described elsewhere (Takeuchi et al., 1995). Amplified products from the cDNA of heterozygous mouse liver were cloned into a pGEM-T plasmid (Promega, Madison, WI). DNA sequencing analysis was performed with an ABI PRISM Dye Terminator Cycle Sequencing Ready Reaction Kit (Perkin-Elmer, Foster City, CA).

Southern and Northern blot analysis and allele-specific genotyping

Northern blot analysis was performed by a conventional method (Maniatis et al., 1989). To isolate mRNA from the brain of each genotype, we used a FastTrack 2.0 kit (Invitrogen, San Diego, CA). mRNA (2 $\mu \mathrm{g})$ was applied to gel electrophoresis. The $5^{\prime}$ (psa-1) and $3^{\prime}$ (psa-2, -3) probes for the Northern blot analysis corresponded to nucleotide positions 316-519, 645-1399, and 2284-2803, respectively (GenBank Accession No. MMU35646). For genotyping, the purification of genomic DNA and genomic Southern blot analysis were performed by a conventional method (Maniatis et al., 1989). Genomic DNA from the tails of each 
mouse genotype was digested with EcoRI and hybridized using psa-2 as a probe.

\section{Aminopeptidase activity assay}

Aminopeptidase activity was assayed as described previously (Dyer et al., 1990; Constam et al., 1995). Cytosolic fractions were prepared as described (Dyer et al., 1990). Protein concentration of the crude extracts was measured by a DC protein assay kit (Bio-Rad, Hercules, CA). Aliquots of the crude extracts corresponding to $100 \mu \mathrm{g}$ of protein were used in the assay. The extracts were incubated with alanyl $p$-nitroanilide (Sigma, St. Louis, MO) to assess aminopeptidase activity. The release of $p$-nitroaniline was measured spectrophotometrically at $405 \mathrm{~nm}$.

\section{Physiological analysis in plasma}

All parameters in plasma were measured by conventional methods, and total triiodothyronine and thyroxine were also measured by enzyme immunoassay at the Veterinary Medical Center, University of Tokyo (Tokyo, Japan). Growth hormone $(\mathrm{GH})$ and insulin-like growth factor (IGF-I) were measured at Koto Biken Co. Ltd. (Tokyo, Japan) by radioimmunoassay.

\section{Behavioral tests}

Behavioral tests were performed between 1 and 6 P.M. in a soundproof room where external noise was greatly reduced (from $-30 \mathrm{~dB}$ at $125 \mathrm{~Hz}$ to $-45 \mathrm{~dB}$ at $500 \mathrm{~Hz}$ ). Adult male mice $(8-15$ weeks old) were used. The room had a clean air conditioning system. All of the apparatus touched by the tested mice were cleaned with deionized water and $70 \%$ ethanol after every test trial.

Rod-walking and wire-hanging tests. To assess motor coordination and traction in mice, rod-walking and wire-hanging tests, respectively, were performed. Briefly, the tested mouse was placed at the center of an elevated wooden rod (diameter, $1.5 \times 60 \mathrm{~cm}$ ). The time spent in moving from the start point, where the mouse was initially placed, to the edge of the rod (length $30 \mathrm{~cm}$ ) was measured. This test was duplicated. For the wire-hanging test, forepaws of the tested mouse were hung on an elevated piano wire. Traction was determined as the ability not to drop from the wire and to remain stable and hanging for over $20 \mathrm{sec}$. This test was also duplicated.

Open-field test. To measure general activity in mice, the open-field test was performed as described previously (Ikegami, 1994). Each mouse was initially placed at the center of the apparatus, and movement was recorded for $30 \mathrm{~min}$.

Elevated plus-maze test. The elevated plus-maze test was conducted basically as described previously (Lister, 1987). For the test, each mouse was initially placed in the center of the maze. Behavior was videotaped during a 15 min test period.

Hot-plate test. The hot-plate test was performed as described elsewhere (Eddy et al., 1950). An electronically controlled stainless steel plate was heated to $55.0 \pm 0.5^{\circ} \mathrm{C}$. A cylinder $(30 \mathrm{~cm}$ high $)$ made of a transparent plastic plate was placed on the hot plate. A mouse was initially put on the center of the hot plate. During the test period, all behaviors were videotaped. The latencies of responses (licking and jumping) were measured.

Tail-flick test. The tail-flick test was performed with an Omnitech Model TF automated tail-flick apparatus (Omnitech, Columbus, OH) following manufacturer's instructions. The latency of a response (tailflicking) to the thermal stimulus produced by $20 \mathrm{~mA}$ was measured. Three repeated trials were conducted for each individual.

\section{Histology and immunodetection}

For X-gal staining, Nissl staining, and immunofluorescence analysis, mice were anesthetized and perfused transcardially first with PBS and then with $0.5 \%$ glutaraldehyde; for immunohistochemistry (IHC), they were then perfused with $4 \%$ paraformaldehyde and $7 \%$ picric acid in PBS. The brains were removed, post-fixed for $4 \mathrm{hr}$ in the same buffer used for perfusion, and stored overnight at $4^{\circ} \mathrm{C}$ in $30 \%$ sucrose in PBS.

For X-gal staining, a series of frozen sections $(20 \mu \mathrm{m})$ was stained for $6.5 \mathrm{hr}$ as described previously (Motoyama et al., 1997). Another series was stained with cresyl violet for Nissl staining. For doubleimmunofluorescence experiments, we used rabbit polyclonal antibodies against $\beta$-galactosidase (gal) (Cappel, West Chester, PA; dilution, 1:500) and monoclonal antibodies against glial fibrillary acidic protein (GFAP) (Sigma; dilution, 1:200), cyclic nucleotide phosphohydrolase (CNP) (Promega; dilution, 1:200), and neuronal nuclei (NeuN) (Chemicon,
Temecula, CA; dilution, 1:200) as primary antibodies. Briefly, incubation with FITC-conjugated secondary antibodies with a specificity for rabbit IgG (Chemicon; $3 \mathrm{hr}$ ), primary monoclonal antibodies (overnight), and finally rhodamine-conjugated secondary antibodies with a specificity for mouse IgG (Chemicon; $3 \mathrm{hr}$ ) was followed by incubation of the sections with primary antibodies against $\beta$-gal (overnight). The IHC analysis was performed as described elsewhere (Motoyama et al., 1997). As primary antibodies, we used antibodies against methionine (met)-enkephalin, leucine (leu)-enkephalin (Chemicon; dilution, 1:5000), and substance P (Takiguchi-Hayashi et al., 1998) (dilution, 1:5000), respectively.

\section{Statistical analyses}

Behavioral abnormalities in the open-field test, the elevated plus-maze test, and the hot-plate test in goku homozygous mice were assessed by one-way or two-way ANOVA. Appropriate pairwise comparisons were performed by the least significant difference (LSD) test. Mean values between the two groups were tested by Student's $t$ test.

\section{RESULTS}

\section{Establishment of the goku mutant mouse line}

To obtain novel genes that are expressed characteristically in the CNS and are involved in neuronal development or functions, we used a mouse gene-trap method described previously (Takeuchi et al., 1995). A trap vector, designated TV2, that has a lacZ gene for monitoring the expression of the trapped gene was introduced into embryonic stem (ES) cells. Chimeric embryos generated by blastocyst injection with a gene-trapped ES cell line, B8, showed strong lacZ gene expression in the CNS at embryonic day 10.5. We established a mouse line by crossing the $B 8$-derived chimeric male mice with BALB/cA females. Heterozygous mice were fertile and showed no apparent abnormalities. Southern blot analysis showed that only one copy of the trap vector was integrated into the genome of the $B 8$ cells (data not shown).

Homozygous mice showed dwarfism and the behavioral abnormalities described below. We named this mouse line goku (after a character of the Japanese cartoon "Dragon Ball") because of the characteristic behaviors associated with homozygous mice. To analyze goku mutant mice in a uniform genetic background, the trapped allele was introduced into BALB/cA background mice by backcrossing heterozygous mice with $\mathrm{BALB} / \mathrm{cA}$ mice. In the experiments described in this manuscript, we used F14-17 heterozygotes as parents for the intercross to obtain goku homozygous mice. No apparent phenotypic differences in goku homozygous mice could be observed throughout the tested generations.

\section{Dwarfism in goku mutant mice and the measurement of physiological parameters in plasma}

We found that goku mutant mice were smaller than their littermates. The body weight at age 7 weeks was $<70 \%$ of that of control littermates (Fig. 1). This difference became apparent first at $\sim 3$ weeks after birth. Interestingly, no appreciable sex difference in body weight could be observed in goku mutant mice (Fig. 1 ). Because this phenotype could arise from malnutrition or endocrine imbalance, we measured the plasma levels of major physiological parameters that are used as reference values (Table 1). In addition, the plasma levels of growth hormone and insulinlike growth factor I were measured (Table 1). No significant differences between wild-type and goku mutants could be observed in any of the parameters tested, suggesting that there are no serious abnormalities in kidney, liver, thyroid, or gastric organs.

\section{goku mutant mice display markedly increased anxiety and analgesia}

We found that goku mutant mice froze or sometimes squeaked when presented with physical stimuli such as poking with fingers 


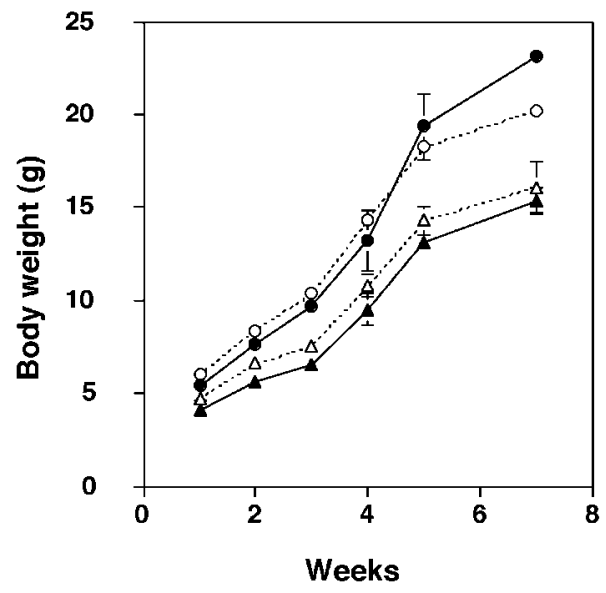

Figure 1. Dwarfism in goku mutant mice. Mean body weights of wildtype males $(\mathbf{\bullet} ; n=13)$, wild-type females $(\bigcirc ; n=13)$, homozygous males $(\mathbf{\Lambda} ; n=10)$, and homozygous females $(\triangle ; n=8)$ by age (Weeks) are plotted. Vertical bars represent SEM.

or tail pulling. To evaluate these behavioral abnormalities, six behavioral tests were conducted. To exclude the involvement of estrous cycling on behavior in female mice, only male mice were used in these tests. In all six tests, wild-type, heterozygous, and goku mutant mice were used, but no significant differences were observed between wild-type and heterozygous mutant mice.

\section{Open-field test, wire-hanging test, and rod-walking test}

In the open-field test, we evaluated spontaneous locomotor activity and the pattern of each genotype under a novel environment. Male mice 8-15 weeks old were tested at 1-6 P.M. The mean locomotor activity in goku mutant mice was reduced to 48.7$57.2 \%$ of wild-type mice in any block of $5 \mathrm{~min}$ throughout the entire $30 \mathrm{~min}$ test (Fig. $2 A$ ). In addition, mean vertical activity, which means rearing behavior, was markedly decreased to 5.4$18.8 \%$ of wild-type mice in each block of 5 min (Fig. $2 B$ ). Fisher's LSD test indicated that locomotion and rearing in goku mutant mice were significantly lower than in heterozygous mice (locomotion, $p<0.01$; rearing, $p<0.01$ ) and wild-type mice (locomotion, $p<0.001$; rearing, $p<0.001$ ), after obtaining significant differences with two-way ANOVA (locomotion, $F_{(2,480)}=161.8, p<$ 0.001 ; rearing, $\left.F_{(2,480)}=90.17, p<0.001\right)$. Moreover, goku mutant mice had a tendency to stay close to the side walls of the open-field box, indicating that goku mutant mice show thigmotaxis (preference for the side walls) (Fig. 2C), which is thought to be an index of anxiety in mice (Treit and Fundytus, 1989).

All abnormalities of goku mutant mice observed in the openfield test during the diurnal periods were also observed during nocturnal periods (data not shown), suggesting that the decreased activities observed in this test were not dependent on the circadian rhythm.

To exclude the possibility that gok $u$ mutant mice suffered from myogenic dysfunctions, we performed a wire-hanging test for traction and a rod-walking test for balance coordination. No significant differences were observed among genotypes (Table 2), indicating that neither significant ataxia nor dysfunctions of motor coordination cause the behavioral abnormalities in goku mutant mice.

\section{Elevated plus-maze test}

A marked decrease in rearing behavior in general activity and an increase in thigmotaxis suggest that goku mutant mice may be emotionally abnormal. We investigated the emotionality of mutant mice using an elevated plus-maze task, which is a useful test for measuring anxiety or fear (Pellow and File, 1986; Lister, 1987). The mean time spent by goku mutant mice in exploring the open arms was significantly less $(56.6 \%)$ than that of wild-type mice (Fig. $3 A)\left(F_{(2,57}=4.35, p<0.05\right.$, one-way ANOVA; $p<$ 0.05 , LSD test). Moreover, the frequency of entry into the open arms was also significantly less in goku mutant mice than in wild-type mice (Fig. $3 B)\left(F_{(2,57)}=4.23, p<0.05\right.$, one-way ANOVA; $p<0.05$, LSD test). On the other hand, the frequency of entry into the closed arms, including turnovers into the same arm, was reduced, but this difference was not significant (Fig. 3C) $\left(F_{(2,57)}=1.43, p=0.25\right.$, one-way ANOVA $)$, indicating that a reduction in general activity did not cause these abnormalities. We observed that goku mutant mice generally trail in the closed area. Interestingly, we also noticed that goku mutant mice sometimes froze once they enter the closed arms. Taken together with data from the open-field test, these results suggest that goku mutant mice display a highly increased anxiety or fear response in novel environments.

\section{Hot-plate and tail-flick tests}

To test more complex organized unlearned behaviors, we performed a hot-plate test because this involves a voluntary purposeful act requiring supraspinal sensory processing (Chapman et al., 1985). The jumping response is the most typical behavior against a nociceptive stimulus mediated at the supraspinal level (Woolfe and Macdonald, 1943; Köning et al., 1996). In goku mutant mice, the mean latency of the jumping response was significantly extended to 1.7 times that in wild-type mice (Fig. 3D) $\left(F_{(2,41)}=\right.$ 17.15, $p<0.001$, one-way ANOVA; $p<0.001$, LSD test). As another parameter of nociceptive response mediated at the supraspinal level, the latency of the hindpaw licking response in goku mutant mice was also extended compared with wild littermates (data not shown).

To assess pain response mediated at the spinal level, we performed the tail-flick test. No significant differences of the mean latency of the tail-flick behavior were observed among three genotypes, indicating that goku mutant mice exhibit a normal pain response at the spinal level (Fig. $3 E$ ).

These data suggest that responses to thermal stimuli mediated at the supraspinal level are hampered in goku mutant mice.

\section{Cloning of the trapped gene}

We identified the trapped gene that is presumably responsible for the abnormal phenotypes in goku mice. It was expected that the insertion of the trap vector arrests transcription of the trapped gene because the trap vector was designed to produce a fusion mRNA. To identify the trapped gene, we used the 5' rapid amplification of cDNA ends (RACE) procedure. The two cDNA clones were isolated from fusion RNA extracted from the liver of a heterozygous mouse. The 74 bp cDNA sequences, which appeared to be derived from the endogenous genomic DNA, were identical in both clones. A comparison with the EMBL and GenBank databases revealed the isolated cDNA to correspond to nucleotide positions 453-526 of Psa cDNA (GenBank Accession No. MMU35646). The fusion site between the Psa cDNA and the trap vector is between nucleotide positions 526 and 527. The region amplified by PCR in the $5^{\prime} \mathrm{RACE}$ procedure was not amplified when genomic DNA from heterozygous mice was used as a template with the same primer set in conventional PCR. This result suggests that the trap vector is inserted in an intron of the 


\begin{tabular}{|c|c|c|c|c|}
\hline Parameter & Wild-type mice & $n$ & Homozygotes & $n$ \\
\hline Red blood cell $\left(\times 10^{4} / \mathrm{mm}^{3}\right)$ & $953.3 \pm 17.8$ & 3 & $1056.3 \pm 48.0$ & 3 \\
\hline White blood cell $\left(\times 10^{3} / \mathrm{mm}^{3}\right)$ & $3.1 \pm 0.9$ & 3 & $2.8 \pm 0.3$ & 3 \\
\hline Total protein $(\mathrm{gm} / \mathrm{dl})$ & $5.9 \pm 0.4$ & 3 & $5.7 \pm 0.3$ & 3 \\
\hline Hematocrit $(\%)$ & $48.7 \pm 0.7$ & 3 & $50.7 \pm 0.5$ & 3 \\
\hline Albumin (gm/dl) & $2.5 \pm 0.1$ & 3 & $2.7 \pm 0.1$ & 3 \\
\hline Aspartate aminotransferase (U/I) & $240 \pm 15.6$ & 3 & $210 \pm 10.6$ & 3 \\
\hline Blood urea nitrogen $(\mathrm{mg} / \mathrm{dl})$ & $33.8 \pm 6.1$ & 3 & $31.0 \pm 2.1$ & 3 \\
\hline Creatinine $(\mathrm{mg} / \mathrm{dl})$ & $0.53 \pm 0.15$ & 3 & $0.47 \pm 0.03$ & 3 \\
\hline Creatine phosphokinase $(\mathrm{mg} / \mathrm{dl})$ & $1365.3 \pm 117.0$ & 3 & $1180 \pm 187.6$ & 3 \\
\hline Glucose $(\mathrm{mg} / \mathrm{dl})$ & $155.5 \pm 14.1$ & 6 & $151.3 \pm 16.8$ & 7 \\
\hline Glutamic-oxaloacetic transaminase (U/I) & $84 \pm 2.4$ & 3 & $68 \pm 5.1$ & 3 \\
\hline Glutamic-pyruvic transaminase (U/I) & $29 \pm 5.7$ & 3 & $23 \pm 9.4$ & 3 \\
\hline $\mathrm{NH}_{3}(\mathrm{mg} / \mathrm{dl})$ & $311 \pm 72.1$ & 6 & $348 \pm 45.4$ & 7 \\
\hline Lactate dehydrogenase (U/I) & $526.3 \pm 75.4$ & 3 & $578.3 \pm 77.0$ & 3 \\
\hline Triglycerides $(\mathrm{mg} / \mathrm{dl})$ & $179 \pm 15.4$ & 6 & $216.6 \pm 26.3$ & 7 \\
\hline Total cholesterol $(\mathrm{mg} / \mathrm{dl})$ & $106.5 \pm 5.1$ & 6 & $107.3 \pm 5.3$ & 7 \\
\hline $\mathrm{Na}^{+}(\mathrm{mEq} / \mathrm{l})$ & $139 \pm 4.9$ & 3 & $141.7 \pm 1.2$ & 3 \\
\hline $\mathrm{K}^{+}(\mathrm{mEq} / \mathrm{l})$ & $6.5 \pm 0.4$ & 3 & $7.8 \pm 0.3$ & 3 \\
\hline $\mathrm{Cl}^{-}(\mathrm{mEq} / \mathrm{l})$ & $107.3 \pm 4.3$ & 3 & $105.5 \pm 0.3$ & 3 \\
\hline $\mathrm{Ca}^{2+}(\mathrm{mEq} / \mathrm{dl})$ & $5.37 \pm 0.04$ & 3 & $5.25 \pm 0.06$ & 3 \\
\hline Total triiodothyronine $(\mathrm{ng} / \mathrm{ml})$ & $0.53 \pm 0.04$ & 6 & $0.61 \pm 0.06$ & 6 \\
\hline Total thyroxine $(\mathrm{ng} / \mathrm{ml})$ & $41.25 \pm 3.15$ & 6 & $37 \pm 1.43$ & 6 \\
\hline Growth factor $(\mathrm{ng} / \mathrm{ml})$ & $10.70 \pm 2.95$ & 4 & $9.90 \pm 2.54$ & 6 \\
\hline Insulin-like growth factor I $(\mathrm{ng} / \mathrm{ml})$ & $475.75 \pm 29.17$ & 4 & $403.17 \pm 33.40$ & 6 \\
\hline
\end{tabular}

Psa gene. To confirm that the trap vector is inserted within the Psa gene, genomic Southern blot analysis was performed (Fig. 4). Genomic DNA from the tails of wild-type, heterozygous, and homozygous mice was digested with endonuclease EcoRI. A probe corresponding to sequences downstream of the insert site (psa-2) yielded a band of $\sim 15 \mathrm{~kb}$ that was detected in both wild-type and heterozygous mice and a band of $\sim 3.8 \mathrm{~kb}$ that was detected in both heterozygotes and homozygotes (Fig. 4). Using the $3^{\prime}$ region of the trap vector as a probe, a band of $3.8 \mathrm{~kb}$ was again detected in both heterozygotes and homozygotes (data not shown). These results show that the trap vector is inserted within the Psa gene and that this analysis enables us to identify all three genotypes in the goku mutant mouse strain.

\section{Transcriptional arrests in goku homozygotes}

We also examined the transcriptional status of Psa gene in goku homozygous mice. Figure 5 shows the results of Northern blot analysis of the mRNA derived from the brains of the three genotypes. With a probe corresponding to sequences upstream of the fusion site (psa-1), a $1.7 \mathrm{~kb}$ band of unknown origin was detected in all three genotypes. In addition, a $4.5 \mathrm{~kb}$ band in wild-type mice, 4.5 and $6.7 \mathrm{~kb}$ bands in heterozygotes, and a single $6.7 \mathrm{~kb}$ band in homozygotes were detected. Because the size of the $4.5 \mathrm{~kb}$ band is the same as that of the Psa mRNA described in Constam et al. (1995), we concluded that the $4.5 \mathrm{~kb}$ band is derived from the intact Psa mRNA. With the lacZ gene as a probe, a $6.7 \mathrm{~kb}$ band was again detected in both heterozygotes and homozygotes (data not shown). These results indicate that the $6.7 \mathrm{~kb}$ band is derived from a fusion mRNA transcribed from the trapped allele. Other probes corresponding to sequences downstream of the fusion site (psa-2 and -3 ) detected a single 4.5 $\mathrm{kb}$ band in wild-type and heterozygous mice, but no signal was detected in homozygotes. These data show that the Psa gene is transcriptionally arrested in goku homozygous mutant mice. Although residues $1-95$ of the Psa protein (total 875 amino acids) (Constam et al., 1995; Tobler et al., 1997) could be produced as a fusion protein with $n e{ }^{\mathrm{r}}$ protein by this arrest, the mutated RNA lacks the region encoding the catalytic domain $\left(\mathrm{HEXXHX}_{18} \mathrm{E}\right.$, residues 353-376). This indicates that Psa activity is disrupted in goku homozygous mice. We designated the Psa allele trapped in goku mice as $P s a^{\text {goku }}$ and designated wild-type, heterozygous, and homozygous mice as $P s a^{+/+}, P s a^{+/ \text {goku }}$, and $P s a^{\text {goku/goku }}$ mice, respectively.

\section{The activities of aminopeptidases sensitive to puromycin in the brain of Psa ${ }^{\text {goku/goku }}$ mice}

Because Northern blot analysis indicated that the Psa gene is disrupted in $P s a^{\text {goku/goku }}$ mice, we assessed this evidence at the protein level. Psa activity, however, cannot be measured directly because there are no known substrates or inhibitors specific for Psa. Therefore, we examined the activities of aminopeptidases sensitive to puromycin in $P s a^{\text {goku/goku }}$ mice. Soluble extracts from the brains of $\mathrm{Psa}^{+/+}$and $P s a^{\text {goku/goku }}$ mice were tested, because Psa activity in the brain is relatively stronger than in other organs (McLellan et al., 1988). We used alanyl- $p$-nitroanilide as a substrate because it is efficiently metabolized by rat Psa and has a relatively high specificity for mouse Psa compared with other $p$-nitroanilides (Constam et al., 1995). The total aminopeptidase activity in the soluble fractions from $P s a^{\text {goku/goku }}$ mice was reduced to $39.5 \%$ of that in $\mathrm{Psa}^{+/+}$littermates (Fig. 6). After preincubating tissue extracts with puromycin as a Psa inhibitor (Hersh, 1985), the aminopeptidase activity in $\mathrm{Psa}^{+/+}$mice was 

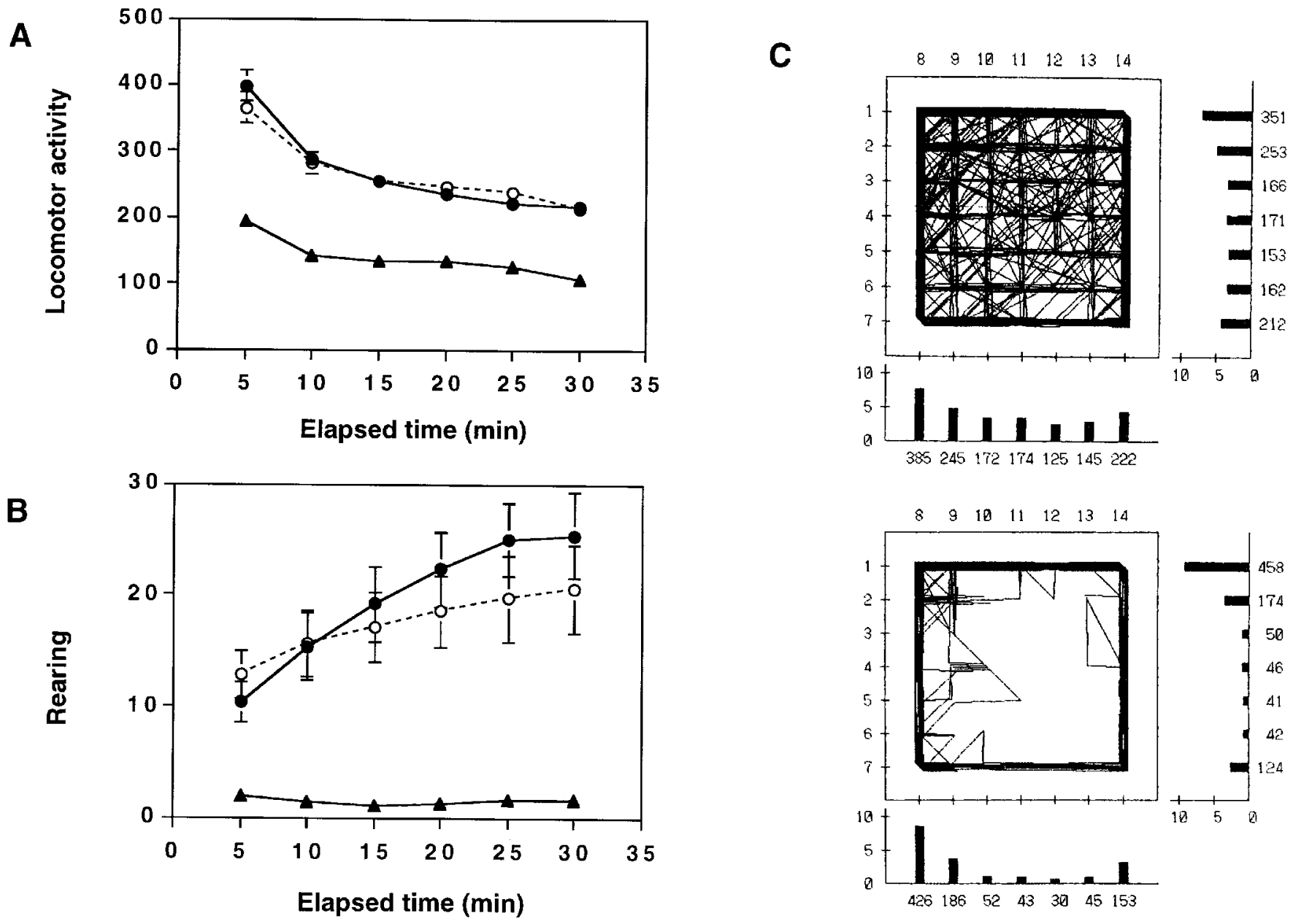

Figure 2. Altered locomotor activity of goku mutant mice as revealed by the open-field test. $A$, Means $( \pm$ SEM) of locomotor activity. $B$, Mean $( \pm$ SEM) frequency of rearing behavior. Wild-type mice $(\bullet ; n=26)$, heterozygotes $(\bigcirc ; n=27)$, and homozygotes $(\boldsymbol{\Delta} ; n=30)$. $C$, Examples of locomotor patterns of wild-type (top) and homozygous (bottom) mice. In the locomotor patterns, the numbers under the bars represent the frequency of photobeam interruption caused by animal movement. One division of the scale on the bars indicates $250(5 \times 50)$ counts. Each mouse was kept in the novel environment with the photocell for $30 \mathrm{~min}$.

\section{Table 2. Balance, coordination, and traction in wild-type, heterozygous,} and homozygous mutant mice

\begin{tabular}{|c|c|c|c|c|}
\hline \multirow[b]{2}{*}{ Genotype } & \multicolumn{2}{|l|}{ Rod-walking test } & \multicolumn{2}{|l|}{ Wire-hanging test } \\
\hline & $\begin{array}{l}\text { Time } \\
(\sec , \text { mean } \pm \mathrm{SEM})^{a}\end{array}$ & $n$ & $\begin{array}{l}\text { Accomplished }{ }^{b} / \\
\text { number of tests }\end{array}$ & $n$ \\
\hline Wild-type mice & $43.85 \pm 22.43$ & 4 & $4 / 6$ & 3 \\
\hline Heterozygotes & $78.92 \pm 47.29$ & 11 & NT & \\
\hline Homozygotes & $50.49 \pm 21.90$ & 6 & $10 / 12$ & 6 \\
\hline
\end{tabular}

\section{NT, Not tested.}

${ }^{a}$ After a training trial, the time of the second trial was recorded.

${ }^{b}$ Mice that were hanging on a wire with their paws for $>20$ sec were counted as accomplished.

${ }^{c}$ Each mouse was tested twice.

reduced depending on the dose of puromycin and reached a plateau level at $12.0 \%$ of the activity in $\mathrm{Psa}^{+/+}$mice without puromycin (Fig. 6). This final activity was supposed to be derived from the aminopeptidases insensitive to puromycin. In $P s a$ goku/goku mice, the activity was finally reduced to almost the same level as that of $\mathrm{Psa}^{+/+}$littermates after preincubation with puromycin. These results indicate that the activity insensitive to puromycin is not affected, whereas the activity sensitive to puromycin is drastically reduced in $P s a^{\text {goku/goku }}$ mice, supporting the notion that Psa activity is disrupted in $P_{s} a^{\text {goku/goku }}$ mice. The decreased aminopeptidase activity dependent on the dose of puromycin in $P_{S a}{ }^{\text {goku/goku }}$ mice was supposed to be derived from the aminopeptidases sensitive to puromycin other than Psa.

\section{Expression pattern of the Psa gene in the brain}

The reporter gene lac $Z$ was introduced into the Psa gene and expressed as a fusion mRNA with Psa transcripts in $P s a^{+/ g o k u}$ and $P s a^{\text {goku/goku }}$ mice. In this way, we can monitor the expression of Psa. Expression in the brain, liver, kidney, spleen, ovary, and testis of adult $P s a^{+/ g o k u}$ mice was examined by whole-mount $\mathrm{X}$-gal staining. Although expression of the Psa gene was observed in all tissues examined, strong expression was detected in the brain and testis (data not shown). These data are consistent with the expression pattern shown by Northern blot (Constam et al., 1995) and with the tissue distribution of Psa activity (McLellan et al., 1988). We examined the distribution of Psa gene expression in the brain in detail, because the phenotypes observed in mutant mice were suspected to result from defects in brain functions. The widespread expression of the Psa gene was observed in the brain. We also doubly stained lacZ-positive cells with markers for neu- 
A

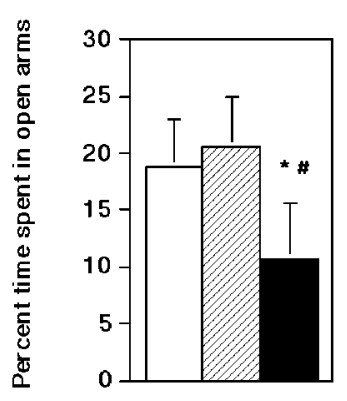

B

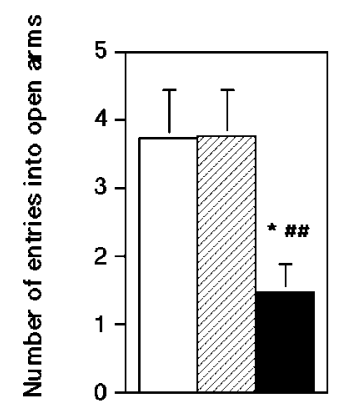

C

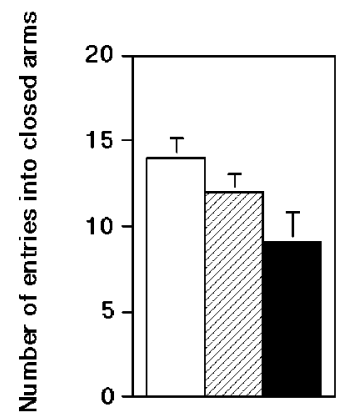

D

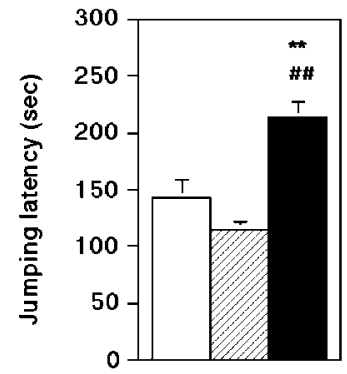

E

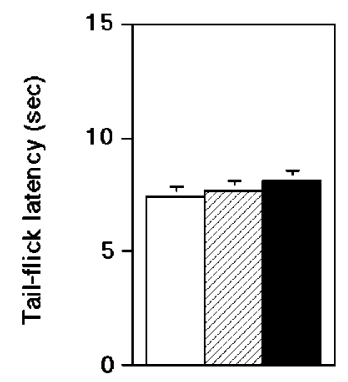

Figure 3. Increased anxiety and nociceptive response to a thermal stimulus in goku mutant mice. $A-C$, Elevated plus-maze test. $A$, Mean $( \pm$ SEM) percentage of time spent in the open arms. $B$, Means $( \pm \mathrm{SEM})$ of total number of entries into the open arms. $C$, Crossings to closed arms (including

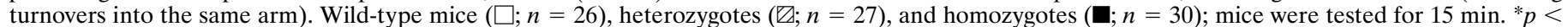
$0.05,{ }^{*} p<0.01$ (wild-type mice vs homozygotes), \# $p<0.05$, \#\# $p<0.01$ (heterozygotes vs homozygotes) (LSD test after one-way ANOVA). $D$, The hot-plate test. Wild-type mice $(\square ; n=12)$, heterozygotes $(\varangle ; n=18)$, and homozygotes $(\square ; n=14)$. Mean latency ( \pm SEM) of jumping is represented. Mice were placed individually on the $55^{\circ} \mathrm{C}$ hot-plate surrounded by a cylindrical wall. $E$, The tail-flick test. Wild-type mice ( $\square$; $\left.n=4\right)$, heterozygotes

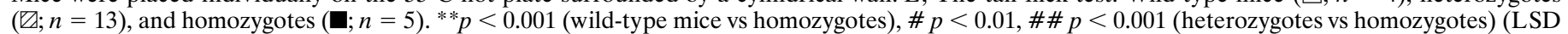
test after one-way ANOVA).

rons, astrocytes, and oligodendrocytes (NeuN, GFAP, and CNP, respectively) (Fig. $7 E-G)$. The Psa gene was found to be expressed in all three cell types (Fig. $7 E-G$ ). Almost all neurons and glial cells in the brain appeared to express the Psa gene. Among neurons, the intensity of expression was not identical. Strong expression was observed in the hippocampus, and striatum (Fig. 7A-D). Three types of neurons could be observed, especially in the thalamus. The first type was strongly positive, the second moderately positive, and the third considerably weaker (Fig. $7 H$ ).

\section{Morphology and immunolocalization of neuropeptides in the brain of Psa ${ }^{g o k u / g o k u}$ mice}

We compared the morphology of the brains of $P s a^{\text {goku/goku }}$ with those of controls by observing sliced sections $(1 \mathrm{~mm})$ of the brains from each genotype. We could not detect any morphological differences. The brains of the $P s a^{\text {goku/goku }}$ mice were smaller than those of controls, but the relative weight of the brain (per total body weight) was not different (data not shown). Although there is a possibility that minute abnormalities were overlooked, these data suggest that Psa does not play a crucial role in brain morphogenesis and that the behavioral impairment observed in $P s a^{\text {goku/goku }}$ mice does not result from morphological defects in the brain.

To evaluate the status of neuropeptides in the brains of $P s a^{\text {goku/goku }}$ mice, we performed immunohistochemical analysis. Although a number of neuropeptides are closely involved in anxiolytic behaviors and pain responses (for review, see Olson et al., 1996; Woolf et al., 1998), we focused on two types of enkephalins, met-enkephalin and leu-enkephalin, because Psa has been purified as a candidate enkephalinase in vivo. Moreover, enkepha- lins are reported to be involved in both anxiety and pain (Köning et al., 1996). In addition, the status of substance P, one of the main modulators of sensitivity to pain, was examined. We tested the immunolocalization of these peptides in the cerebrum of $\mathrm{Psa}^{+/+}$and $P s a^{\text {goku/goku }}$ mice. No apparent differences in the distribution patterns or intensity could be detected between these genotypes. This immunoreactivity was apparent in the subcommissural ventral pallidum in which these peptides colocalize (Heimer et al., 1995) (Fig. 8). This shows that the expression of these three neuropeptides is not severely affected in $P s a^{\text {goku/goku }}$ mice.

\section{DISCUSSION}

Behavioral and other physiological traits are adequately complex and occasionally variable, and a number of genes probably contribute to them. Therefore, to understand the mechanisms of unusual phenotypes observed in the mutant mice, it is important to consider the effects of background genes (Gerlai, 1996). We have proceeded $>14$ backcrosses to minimize the effects of cosegregating loci and genetic background on the phenotypes in $P s a^{\text {goku/goku }}$ mice. Although the repeated backcrosses do not completely eliminate the influence of the background gene on the phenotypes in the mutants, $P s a^{\text {goku/goku }}$ mice provide a genetically preferable means for the study of the involvement of Psa in mammalian growth and behavior.

\section{Dwarfism and physiological condition in Psa ${ }^{\text {goku/goku }}$ mice}

$P s a^{\text {goku/goku }}$ mice showed apparent dwarfism from 3 weeks after birth (Fig. 1). Because an adequate supply of GH is essential for the control of normal body growth in mammals, and some dwarf 
A

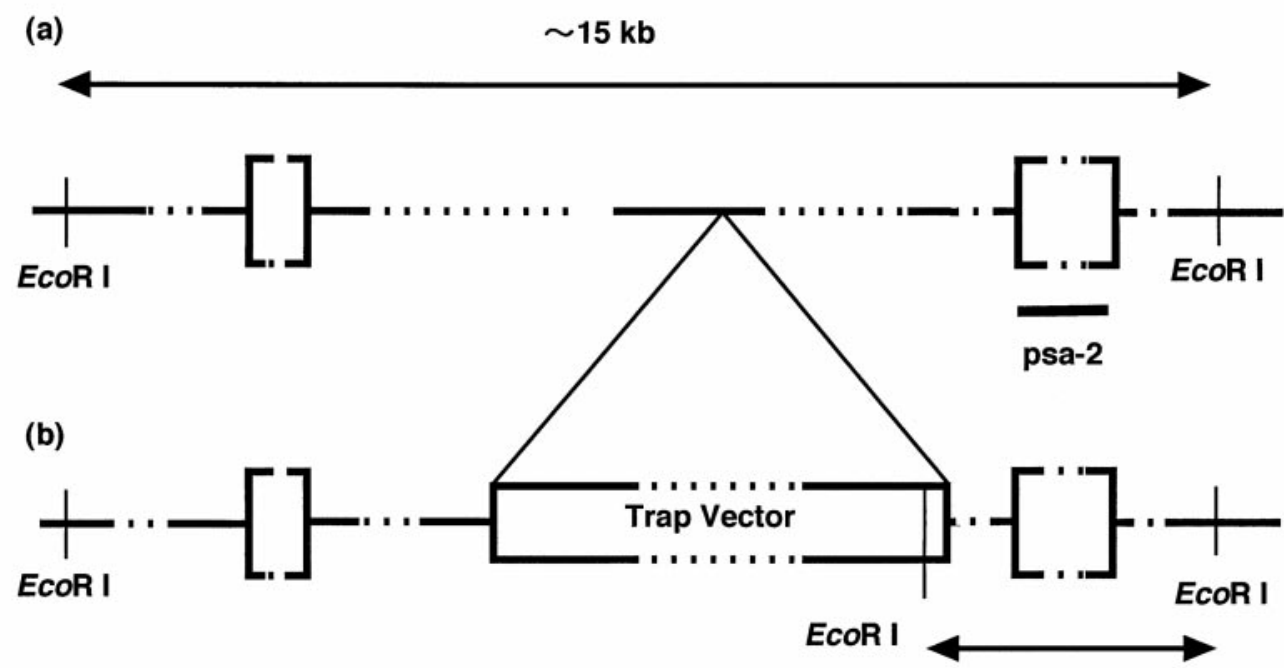

$3.8 \mathrm{~kb}$

B

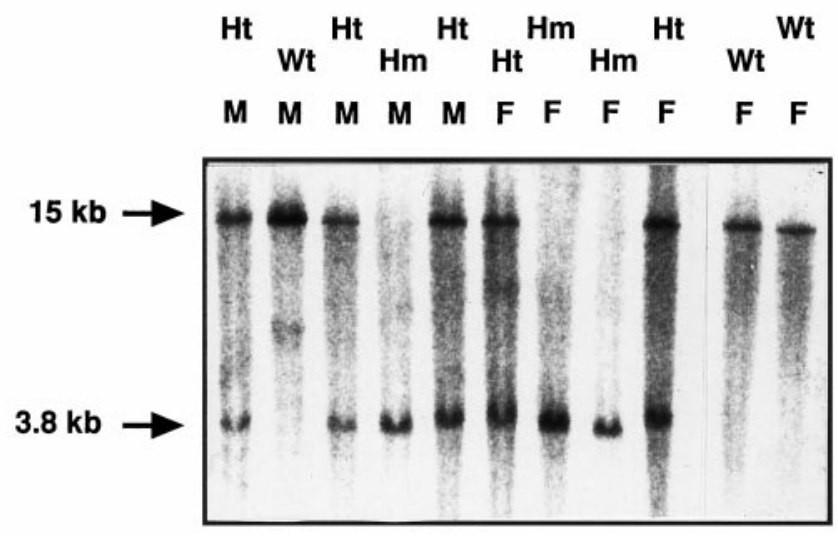

Figure 4. A trap vector was inserted in the Psa gene. A, The schema for wild and trapped alleles. $a$, Wild-type allele; $b$, trapped allele. Bold bar (psa-2) represents the probe for Southern blot analysis that recognizes an EcoRI fragment of $\sim 15 \mathrm{~kb}$ from the wild allele and a $3.8 \mathrm{~kb}$ fragment from the trapped allele. Open squares represent exons of the Psa gene. B, Examples of Southern blot analyses of the genotypes. Lanes 1-11, Results of individual mice. Genotype and sex are shown at the top of each lane. W, Wild-type mouse; $H t$, heterozygote; Hm, homozygote; $M$, male; $F$, female.

mouse strains show defects in GH (Eicher and Beamer, 1976, 1980), we investigated the plasma levels of GH and IGF-I, which is a growth factor regulated by GH. There were no significant differences in plasma GH and IGF-I levels between $\mathrm{Psa}^{+/+}$and $P s a^{\text {goku/goku }}$ mice. No plasma levels of a number of parameters used as reference values showed any significant differences between genotypes (Table 1), suggesting that the phenotypes observed in $P s a^{\text {goku/goku }}$ mice are not derived from dysfunctions in the digestive organs.

A previous study reported that puromycin arrests the cell cycle of COS cells and induces the cells to undergo apoptosis (Constam et al., 1995), and the authors suggested that the inhibition of the activity of Psa or other aminopeptidases by puromycin may arrest the cell cycle and induce apoptosis. From their study, we can speculate a possibility that dwarfism of $\mathrm{Psa}^{\text {goku/goku }}$ mice results from the impairment of the cell cycle or from induced apoptosis. In fact, several knockout mice carrying mutated genes associated with the cell cycle events show abnormalities in growth (Sicinski et al., 1995; for review, see Raff, 1996)

Although the molecular roles of Psa in growth remain unknown, it is interesting that no sexual dimorphism in body weights was observed in $P s a^{\text {goku/goku }}$ mice (Fig. 1). This phenotype was distinguished from some other spontaneous dwarf mouse strains. Taken together with the observation that the mutants were infertile in both sexes (T. Osada and T. Takeuchi, unpublished data), dwarfism with no sexual difference in $P s a^{\text {goku/ }}$ goku mice may arise from imbalance of the endocrine system independent of $\mathrm{GH}$ and IGF-I. In fact, pituitary glycoprotein hormone $\alpha$-subunit gene knockout mice, which lack biologically active pituitary thyrotropin and gonadotropins, show dwarfism with no sex difference, in addition to hypogonadism and hypothyroidism (Kendall et al., 1995). Although $\mathrm{Psa}^{\text {goku/goku }}$ mice exhibited comparable levels of thyroxine, which is produced in thyroid in response to thyrotropin stimulation, there is a possi- 
A

a) Wild transcripts (4.5 kb)

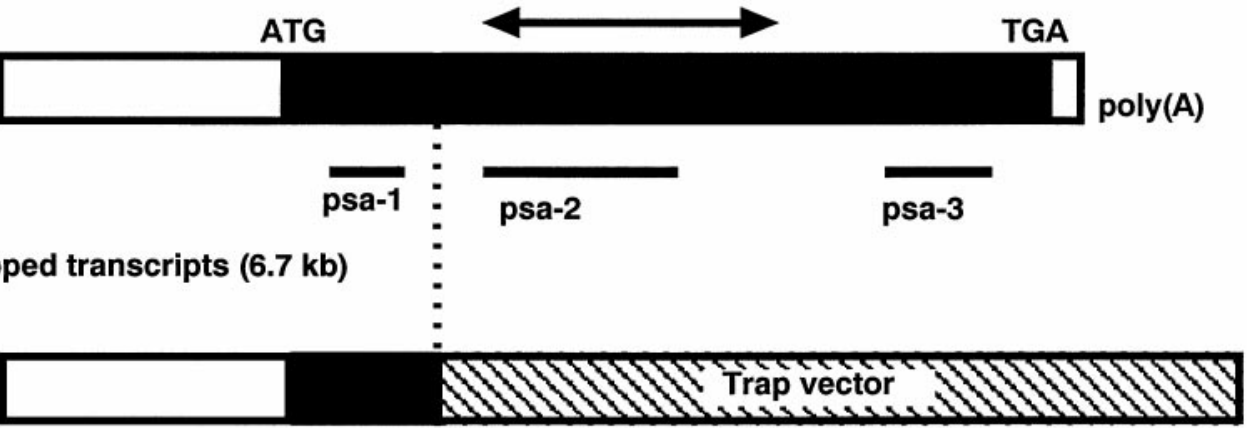

B
Probe :
psa-1
psa-2
psa-3
B-actin
(kb)
W Ht Hm
W Ht Hm
W Ht Hm
W Ht Hm

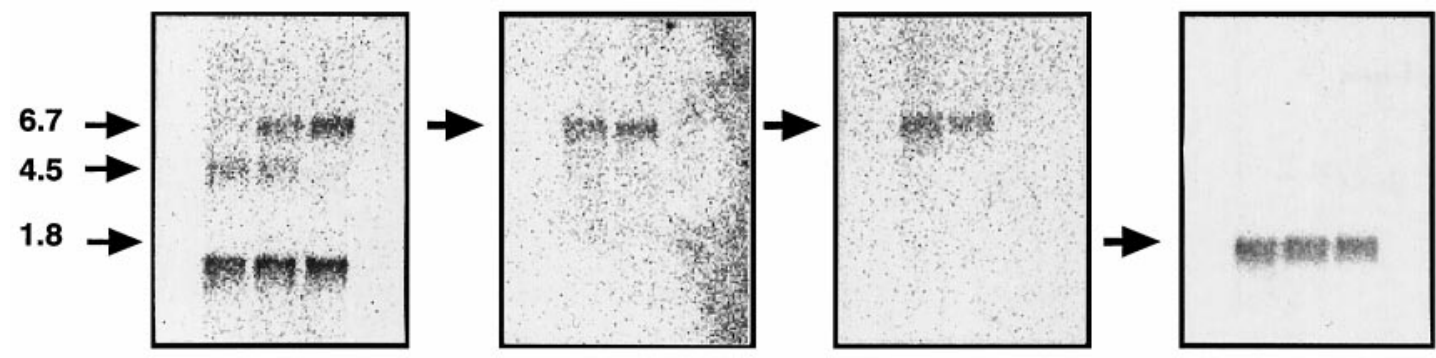

Figure 5. Transcriptional arrest of the Psa gene in goku mutant mice. $A$, Schema for transcriptional arrest. $a$, Wild-type transcript; $b$, trapped transcript. Filled horizontal bar, Coding region of the Psa gene; hatched horizontal bar, region derived from the trapped vector; double-headed arrow, region encoding the catalytic domain containing $\operatorname{HEXXHX}_{18} \mathrm{E}$; psa-1, -2, -3, probes for Northern blots analysis. $B$, Northern blot analysis. Poly $\left(\mathrm{A}^{+}\right) \mathrm{RNA}(2 \mu \mathrm{g})$ from the brains of 8 -week-old mice were electrophoresed. Human $\beta$-actin cDNA was used as a control. W, Wild-type mice; $H t$, heterozygotes; $H m$, homozygotes.

bility that other hormonal signalings are hampered in the mutants.

\section{Behavioral abnormalities in Psagoku/goku mutant mice}

We evaluated behavioral impairments in Psa-deficient mice by six behavioral tests (rod-walking, wire-hanging, open-field, elevated plus-maze, hot-plate, and tail-flick tests). These tests allowed us to characterize two major features of $P s a^{\text {goku/goku }}$ mice: emotional impairment under a novel environment and the increase of the analgesia. We discuss each feature observed in $P s a^{\text {goku/goku }}$ mice below.

\section{Emotional impairment under a novel environment}

Decreased locomotor activity in the open-field test and increased anxiolytic features in the open-field test and elevated plus-maze test have been reported previously in knockout mouse strains that have impairments in learning and memory or other integrative brain functions such as emotion (for review, see Nelson and Young, 1998). There is no evidence that the similarities in behavioral impairments observed in $P s a^{\text {goku/goku }}$ mice and other mutants originate from the same defects. Because metenkephalin and leu-enkephalin have been reported as possible Psa targets (Hersh and McKelvy, 1981), and a report on enkephalin knockout mice shows that enkephalins are involved in anxiety

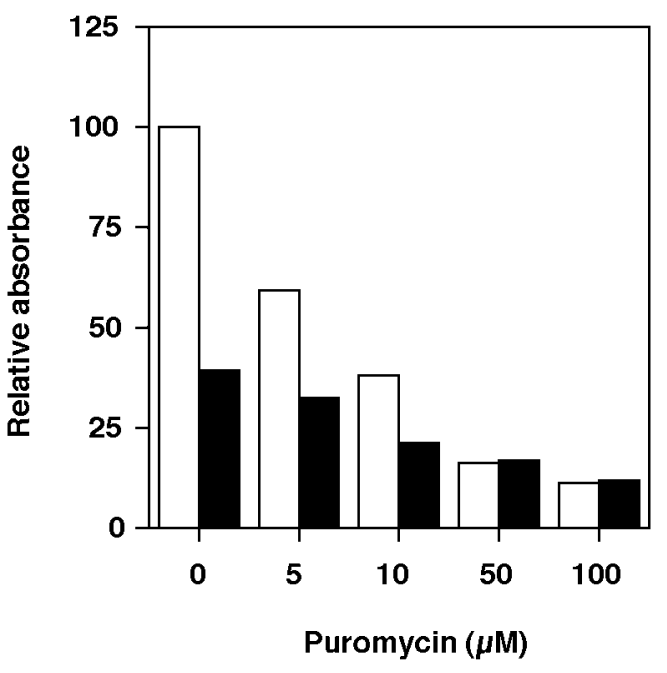

Figure 6. Puromycin-sensitive aminopeptidase activity is decreased in $P s a^{\text {goku/goku }}$ mice. The aminopeptidase activity in brain extracts from $P s a^{+/+}$(open columns; $n=8$ ) and $P s a^{\text {goku/goku }}$ mice (filled columns; $n=$ 4) was incubated with alanyl-p-nitroanilide as a substrate. The effect of puromycin as an inhibitor for Psa with various concentrations was also measured. The results are shown as the relative absorbance in which the value of $\mathrm{Psa}^{+/+}$with no puromycin added is defined as 100 . 

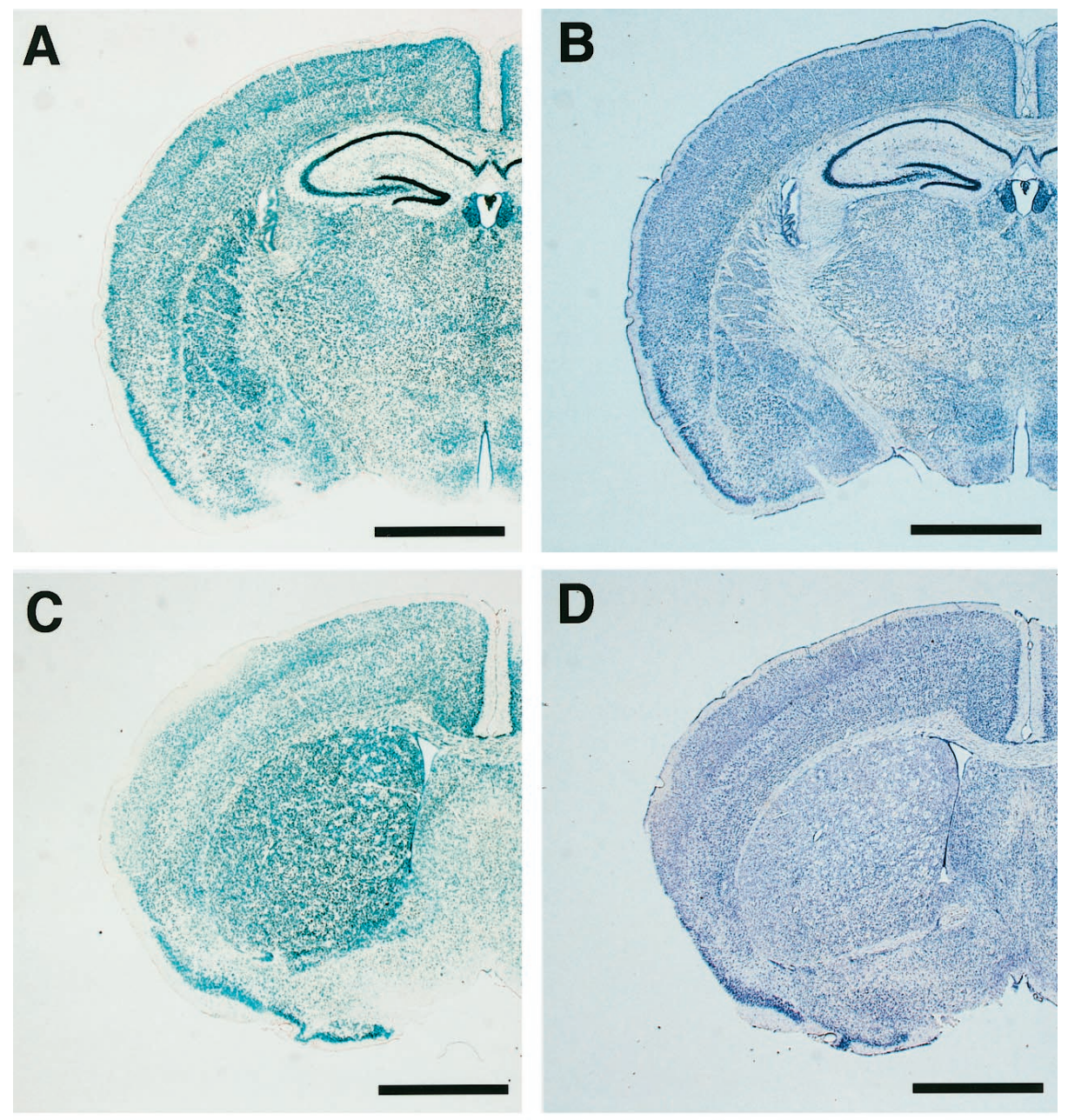

Figure 7. Expression patterns of the Psa gene in the adult brain of $P s a^{+/ g o k u}$ mice. $A, C$, Brain sections $(20 \mu \mathrm{m})$ stained with X-gal. $B, D$, Sections, $60 \mu \mathrm{m}$ anterior to $A$ and $C$, respectively, stained with cresyl violet. $E-G$, Dual color immunofluorescence micrograph images of $\beta$-gal (green; $E-G)$ and markers (red) $(E, \mathrm{NeuN} ; F$, GFAP; $G, C N P)$. All neurons $(E)$ and glias (arrows in $F$ and $G$ ) investigated were double positive (orange). $H$, High-power views in the thalamus of section in $B$ using differential interference microscopy. Strong (arrows), moderate (arrowheads), and weak (asterisks) positive cells for $\beta$-gal activity. Scale bars: $A-D, 1.6 \mathrm{~mm}$; $E-G, 10 \mu \mathrm{m} ; H, 100 \mu \mathrm{m}$.
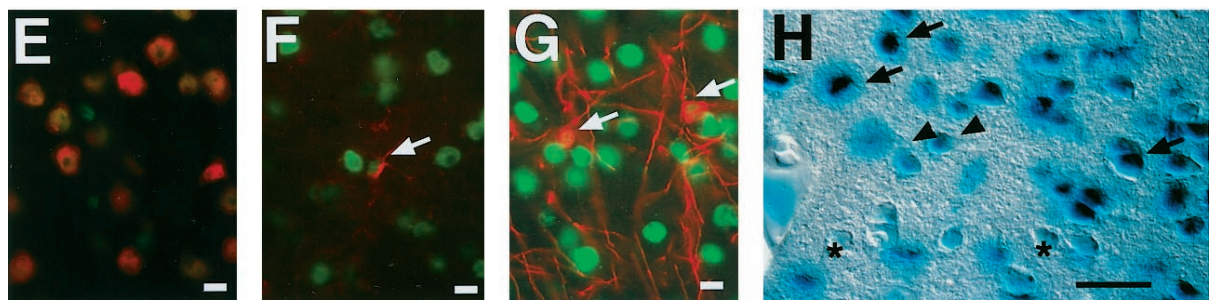

and pain (Köning et al., 1996), the expression patterns of these neuropeptides in the brains of $P s a^{\text {goku/goku }}$ mice were examined by the IHC analysis. Comparable levels and expression patterns were found in both $P s a^{+/+}$and $P s a^{\text {goku/goku }}$ mice (Fig. $8 A-D$ ), although a possibility that some difference between the genotypes was undetectable by IHC cannot be excluded. Because Psa hydrolyzes N-terminal amino acids of oligopeptides with a broad spectrum, it is also possible that neuropeptides other than enkephalins may affect normal behavior in mammals.

\section{Increase in analgesia}

Psa is expressed in the brain broadly (Fig. 7A,C), in spinal cord, and in dorsal root ganglion (data not shown). The increased latency of the jumping response and normal reflex response to noxious thermal stimuli suggests that the increase in analgesia in $P s a^{\text {goku/goku }}$ mice derives from abnormalities in the brain. Because substance $\mathrm{P}$ has been studied extensively as a neuropeptide that modulates pain responses (for review, see Woolf et al., 1998), we assessed the expression of this peptide in the brains of $P s a^{\text {goku/goku }}$ mice by IHC. No apparent alternations could be detected (Fig. $8 E, F$ ). It is important to analyze the status of substance $\mathrm{P}$ after nociceptive stimulus to examine metabolic defects or synthetic abnormalities of substance $\mathrm{P}$ in $P s a^{\text {goku/goku }}$ mice. It is also possible that other molecules in the brain affected by Psa deficiency might be involved in the analgesic effect observed in mutants. Therefore, intensive studies are needed to elucidate the molecular mechanisms of the altered response to thermal stimuli in $P s a^{\text {goku/goku }}$ mice.

Pain and emotion are believed to be closely connected to one another. Our study suggests that Psa in the brain plays important roles in the regulation of these phenomena.

\section{Psa gene expression in the brain}

The expression pattern of the Psa gene in the brain is important because the Psa activity in the brain is reported to be higher than in other organs (McLellan et al., 1988). Moreover, behavioral impairments of $\mathrm{Ps}^{\text {goku/goku }}$ mice are suggested to result from defects in brain functions. A previous study involving in situ 

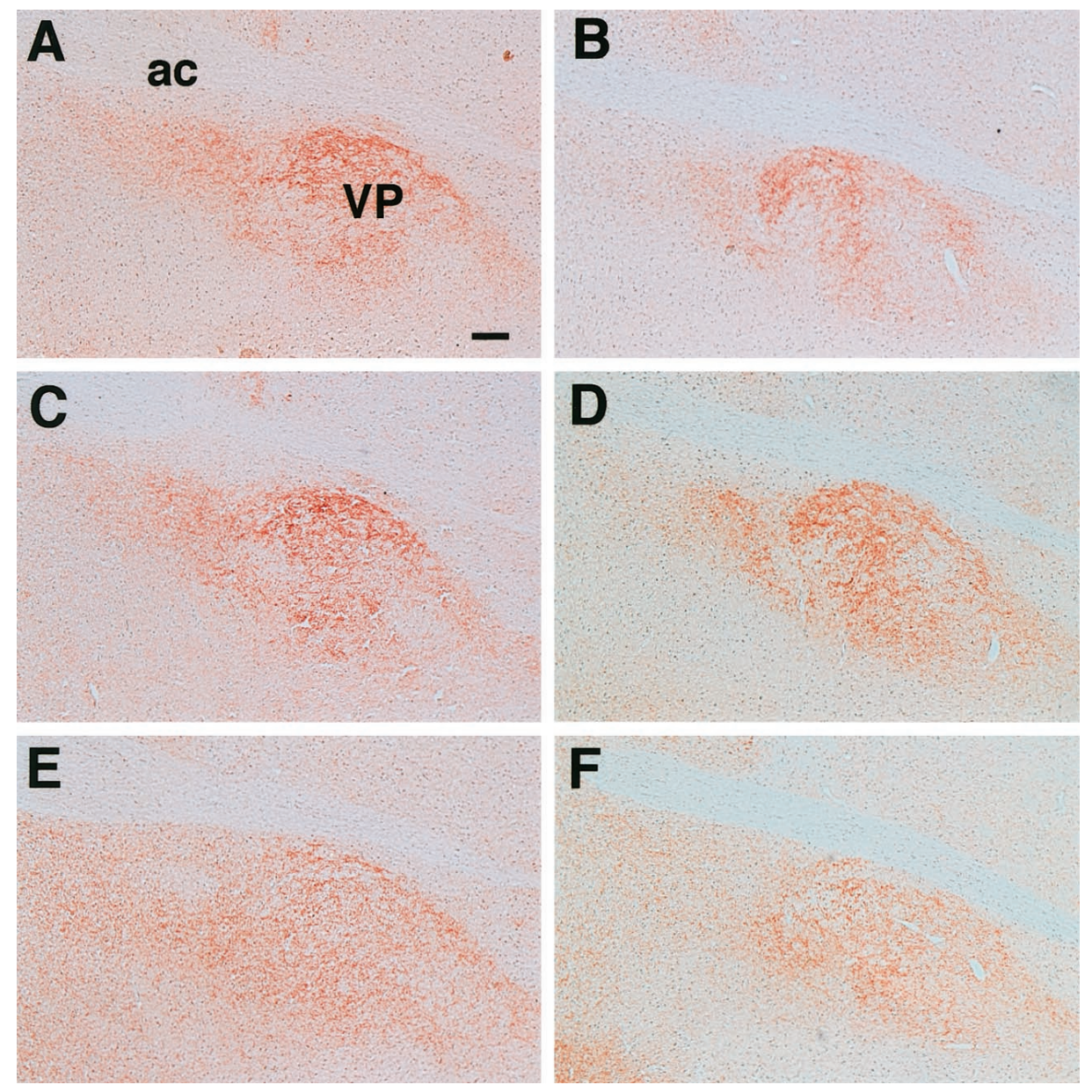

Figure 8. Immunolocalization of enkephalins and substance $\mathrm{P}$ in the subcommissural ventral pallidum $(V P)$. Sections from $P_{s a} a^{+/+}(A, C, E)$ and $P$ sa goku/goku mice $(B, D, F)$, stained with antibodies against met-enkephalin $(A, B)$, leu-enkephalin $(C, D)$, and substance $\mathrm{P}(E$, $F$ ). $a c$, Anterior commissure, posterior. Scale bar, $100 \mu \mathrm{m}$. hybridization analysis reported that the Psa gene in the human brain is expressed preferentially in neurons (Tobler et al., 1997). We observed that the Psa gene is also expressed in astrocytes and oligodendrocytes in addition to neurons (Fig. $7 E-G$ ). In neurons, the intensity of expression was not identical, although almost all neurons appeared to express the Psa gene. In particular, intensive Psa gene expression in neurons was detected in the striatum and hippocampus (Fig. 7A,C). These data suggest that Psa may play some basic roles in the cell physiology of the brain, as well as more specific roles in those types of the cells in which Psa gene expression is strong. Because peptides that exist predominantly in the striatum or hippocampus are known to be involved in normal behavior (for review, see Nelson and Young, 1998), further analysis of the interaction of these peptides with Psa should prove interesting.

\section{Psa status in Psa ${ }^{\text {goku/goku }}$ mice}

We found an additional transcript $(1.7 \mathrm{~kb})$, possibly an alternatively spliced isoform, in addition to the Psa transcript $(4.5 \mathrm{~kb})$. However, the molecule from the transcript was suggested to lack aminopeptidase activity because it does not contain the catalytic domain of Psa.

Northern blot analyses also showed that transcriptional arrest occurs in the Psa gene of $P s a^{\text {goku/goku }}$ mice. Transcripts encoding the catalytic domain of Psa were not detectable in Psa goku/goku mice. To elucidate Psa status in the mutants, aminopeptidase activity in the brains of each genotype was measured. The activity using the alanyl- $p$-nitroanilide as a substrate showed a drastic decrease in activity in $P s a^{\text {goku/goku }}$ mice. In contrast, puromycininsensitive activity ( $\sim 12 \%$ of total activity) did not differ from that in $\mathrm{Psa}^{+/+}$mice. These results suggest that the decreased activity observed in $P s a^{\text {goku/goku }}$ mice $(\sim 60 \%)$ corresponds to the Psa activity in $\mathrm{Psa}^{+/+}$mice. On the other hand, a decrease in the puromycin dose-dependent activity $(\sim 28 \%)$ was also observed in $P s a^{\text {goku/goku }}$ mice. This decreased activity is thought to derive from puromycin-sensitive aminopeptidases but not from Psa. Thus, we can classify the aminopeptidase activity into Psadependent, Psa-independent but puromycin-sensitive, and puromycin-insensitive in all tissues using $P_{s} a^{\text {goku/goku }}$ mice. Recently, a novel aminopeptidase, which is located in abundance in the brain synaptosomes and whose activity is inhibited by puromycin, was identified by Hui et al. (1998) as a puromycin-sensitive aminopeptidase other than Psa.

Taken together with the molecular and biochemical analyses, we conclude that the Psa gene is functionally disrupted in $P s a^{\text {goku/goku }}$ mice. Therefore, the observed abnormalities in $P s a^{\text {goku/goku }}$ mice were suggested to originate from the inactivation of Psa. Because the molecular functions and substrates of Psa in vivo remain unknown, this mutant would be a useful tool for gaining new insights into the physiological functions of the Psa gene in mammals.

\section{REFERENCES}

Chapman CR, Casey KL, Dubner R, Foley KM, Gracely RH, Reading AE (1985) Pain measurement: overview. Pain 22:1-31.

Constam DB, Tobler AR, Rensing-Ehl A, Kemler I, Hersh LB, Fontana 
A (1995) Puromycin-sensitive aminopeptidase. Sequence, analysis, expression, and functional characterization. J Biol Chem 270:26931-26939.

Dyer SH, Slaughter CA, Orth K, Moomaw CR, Hersh LB (1990) Comparison of the soluble and membrane-bound forms of the puromycinsensitive enkephalin-degrading aminopeptidases from rat. J Neurochem 54:547-554.

Eddy NB, Touchberry CF, Lieberman JE (1950) Synthetic analgesics. I. Methadone isomer and derivatives. J Pharmacol Exp Ther 98:121-137.

Eicher EM, Beamer WG (1976) Inherited ateliotic dwarfism in mice. J Hered 67:87-91.

Eicher EM, Beamer WD (1980) New mouse $d w$ allele: genetic location and effects of lifespan and growth hormone levels. J Hered 71:187-190.

Gerlai R (1996) Gene-targeting studies of mammalian behavior: is it the mutation or the background genotype? Trends Neurosci 19:177-181.

Gossler A, Joyner AL, Rossant J, Skarnes WC (1989) Mouse embryonic stem cells and reporter constructs to detect developmentally regulated genes. Science 244:463-465.

Heimer L, Zahm DS, Alheid F (1995) Basal ganglia. In: The rat nervous system, Ed 2 (Paxinos G, ed), pp 579-628. San Diego: Academic.

Hersh LB (1985) Characterization of membrane-bound aminopeptidases from rat brain: identification of the enkephalin-degrading aminopeptidase. J Neurochem 44:1427-1435.

Hersh LB, McKelvy JF (1981) An aminopeptidase from bovine brain which catalyzes the hydrolysis of enkephalin. J Neurochem 36:171-178.

Hui KS, Saito M, Hui M (1998) A novel neuron-specific aminopeptidase in rat brain synaptosomes. Its identification, purification, and characterization. J Biol Chem 273:31053-31060.

Hui M, Budai ED, Lajtha A, Palkovits M, Hui K-S (1995) Changes in puromycin-sensitive aminopeptidases in postmortem schizophrenic brain regions. Neurochem Int 4/5:433-441.

Ikegami S (1994) Behavioral impairment in radial-arm maze learning and acetylcholine content of the hippocampus and cerebral cortex in aged mice. Behav Brain Res 65:103-111.

Kendall SK, Saumuelson LC, Saunders TL, Wood RI, Camper SA (1995) Targeted disruption of the pituitary glycoprotein hormone $\alpha$-subunit produces hypogonadal and hypothyroid mice. Genes Dev 9:2007-2019.

Kitajima K, Takeuchi T (1999) Mouse gene trap approach: identification of novel genes and characterization of their biological functions. Biochem Cell Biol, in press.

Köning M, Zimmer AM, Steiner H, Holmes PV, Crawley JN, Brownstein MJ, Zimmer A (1996) Pain, anxiety and aggression in mice deficient in pre-proenkephalin. Nature 383:535-538.
Lister RG (1987) The use of a plus-maze to measure anxiety in the mouse. Psychopharmacology 92:180-185.

Maniatis T, Fritsch EF, Sambrook J (1989) Molecular cloning: a laboratory manual. Cold Spring Harbor, NY: Cold Spring Harbor Laboratory.

McLellan S, Dyer SH, Rodriguez G, Hersh LB (1988) Studies on the tissue distribution of the puromycin-sensitive enkephalin-degrading aminopeptidase. J Neurochem 51:1552-1559.

Motoyama J, Kitajima K, Kojima M, Kondo S, Takeuchi T (1997) Organogenesis of the liver, thymus, spleen is affected in jumonji mutant mice. Mech Dev 66:27-37.

Nelson RJ, Young KA (1998) Behavior in mice with targeted disruption of single genes. Neurosci Biobehav Rev 22:453-462.

Olson GA, Olson RD, Kastin AJ (1996) Endogenous opiates: 1995. Peptides 17:1421-1466.

Pellow S, File SE (1986) Anxiolytic and anxiogenic drug effects on exploratory activity in an elevated plus-maze: a novel test of anxiety in the rat. Pharmacol Biochem Behav 11:99-106.

Raff MC (1996) Size control: the regulation of cell numbers in animal development. Cell 86:173-175.

Sicinski P, Donaher JL, Parker SB, Li T, Fazeli A, Gardner H, Haslam SZ, Bronson RT, Elledge SJ, Weinberg, RA (1995) Cyclin D1 provides a link between development and oncogenesis in the retina and breast. Cell 82:621-630.

Takeuchi T, Yamazaki Y, Katoh-Fukui Y, Tsuchiya R, Kondo S, Motoyama J, Higashinakagawa T (1995) Gene trap capture of a novel mouse gene, jumonji, required for neural tube formation. Genes Dev 9:1211-1222.

Takiguchi-Hayashi K, Sato M, Sugo N, Ishida M, Sato K, Uratani Y, Arimatsu Y (1998) Latexin expression in smaller diameter primary sensory neurons in the rat. Brain Res 801:9-20.

Tobler AR, Constam DB, Schmitt-Graff A, Malipiero U, Schlapbach R, Fontana A (1997) Cloning of the human puromycin-sensitive aminopeptidase and evidence for expression in neurons. J Neurochem 68:889-897.

Treit D, Fundytus M (1989) Thigmotaxis as a test for anxiolytic activity in rats. Pharmacol Biochem Behav 31:959-962.

Woolf CJ, Mannion RJ, Neumann S (1998) Null mutations lacking substance: elucidating pain mechanisms by genetic pharmacology. Neuron 20:1063-1066.

Woolfe G, Macdonald AD (1943) The evaluation of the analgesic action of pethidine hydrochloride (Demerol). J Pharmacol Exp Ther 80:300307. 